\title{
A systematic literature review and meta-analysis of impella devices used in cardiogenic shock and high risk percutaneous coronary interventions
}

Background: To perform a meta-analysis on pooled survival and complications rates of Impella ${ }^{\circledR}$ heart pumps (Abiomed Inc., Danvers, USA) use in cardiogenic shock and high-risk coronary percutaneous coronary intervention $(\mathrm{PCl})$.

\begin{abstract}
Methods and Findings: Articles were searched in Medline, Medline In-Process, EMBASE and the CENTRAL bibliographic databases on the 30th April, 2017. Prospective and retrospective studies with $\geq 10$ patients supported with Impella. Survival and complication rates were pooled. The literature review identified 33 articles. Data on patient characteristics, indication of support, type of Impella device and outcomes were extracted. A random effect was used to pool the various outcomes. Low heterogeneity $(I 2 \leq 0.25)$ results are presented. A total of 2,827 patients $(40.5 \%$ cardiogenic shock, $59.5 \%$ high-risk $\mathrm{PCl}$ ) were included (mean age $64.9 \pm 11.4$, male $74.6 \%$ ). In the cardiogenic shock indication, survival rate to 90 and 180 days was $62.6 \%$ and $58.3 \%$, respectively; the rates of hemolysis and device malfunction were $8.8 \%$ and $2.5 \%$, respectively. In the high-risk PCl indication, the 30 day major adverse cardiac and cerebrovascular event (MACCE) rate was $15.3 \%$ with a 30 day survival, stroke, myocardial infarction and repeat revascularization rates of $92.2 \%, 0.3 \%, 13.5 \%$ and $1.6 \%$, respectively. Hemolysis and device malfunction affected respectively $0.7 \%$ and $1.4 \%$ of the high-risk $\mathrm{PCl}$ patients.
\end{abstract}

Conclusions: This is the largest meta-analysis summarizing the literature outcome data of Impella heart pumps. The present study demonstrates very encouraging survival in cardiogenic shock patients and very good 30 day outcomes in patients undergoing prophylactic support for high-risk $\mathrm{PCl}$.

Keywords: Heart failure - Cardiac disease - Intervention - Surgery - Transplantation - Quality and outcomes - Vascular disease $\cdot$ Acute coronary syndromes $\bullet$ Coronary artery disease

\section{Introduction}

Short-term mechanical circulatory support (MCS) is an established treatment option across a diverse range of clinical indications including cardiogenic shock and high risk percutaneous coronary interventions (HRPCI) [1-4]. The Impella platform of left ventricular assist devices (Abiomed, Inc., Danvers, Massachusetts) are minimally invasive, catheter-based, axial flow pumps which directly unload the left ventricle by driving blood from the left ventricle into the ascending aorta. Impella devices were introduced onto the market in 2003 in Europe and 2008 in the United States. Since the advent of the first generation of Impella pumps a number of revised devices have since become available, including the Impella 2.5, Impella CP (cardiac power), Impella 5.0 and Impella LD (Left direct) (Table 1) [5].

Whilst the current evidence base supporting the survival benefits and documenting complications associated with Impella support in cardiogenic shock and HRPCI is growing, these studies tend to be limited by under-powering and/or design, with the majority of the available data being sourced from small clinical trials or case series [6,7]. Whilst Impella has been available since 2003, no contemporary systematic overview of the combined safety and effectiveness profile
Jonathan Hill', Adrian Banning², Francesco Burzotta ${ }^{3}$, Alaide Chieffo $^{4}$, Bernhard Schieffer ${ }^{5}$, Andreas Schäfer ${ }^{6}$, Natalia M Stelmaszuk-Zadykowicz ${ }^{7}$, Sun Sun ${ }^{7-9}$, Tim Spelman ${ }^{7,10^{*}}$, Sagar Doshi ${ }^{11}$, Nikos Werner ${ }^{12}$, Markus W Ferrari' ${ }^{13}$, Alastair Proudfoot ${ }^{14}$, Laurent Baradon ${ }^{15}$, Theodore Schreiber ${ }^{16}$, Perwaiz Meraj ${ }^{17}$, Mark B Anderson ${ }^{18}$, William W O'Neill ${ }^{19}$

${ }^{1}$ King's College Hospital and King's Health Partners Academic Health Sciences, London, UK

${ }^{2}$ Department of Cardiology, John Radcliffe Hospital, Cardiology, Oxford, UK ${ }^{3}$ Institute of Cardiology, Catholic University of Sacred Heart, Rome, Italy

${ }^{4}$ Interventional Cardiology Unit, San Raffaele Hospital, Milan, Italy

${ }^{5}$ Department of Cardiology, Angiology and Intensive Care, Philipps University Marburg Germany

${ }^{6}$ Department of Cardiology and Angiology, Hannover Medical School, Hannover, Germany

${ }^{7}$ Synergus AB, Danderyd, Sweden ${ }^{8}$ Health Outcomes and Economic Evaluation Research Group, Center for Healthcare Ethics, Department of Learning, Information, Management and Ethics. Karolinska Institutet, Stockholm, Sweden ${ }^{9}$ Division of Epidemiology and Global Health, Department of Public Health and Clinical Medicine, Umeå University, Umeå Sweden

${ }^{10}$ Department of Clinical Neuroscience, Karolinska Institute, Stockholm, Sweden

${ }^{11}$ Department of Cardiology, Queen Elizabeth Hospital Birmingham,

Birmingham, UK

${ }^{12}$ Heart Center, Department of Medicine II, University Hospital Bonn, Bonn, Germany

${ }^{13}$ Helios Dr. Horst Schmidt Kliniken,

Wiesbaden, Germany

${ }^{14}$ Saint Bartholomew's Hospital, Critical Care Department, West Smithfield, London, UK ${ }^{15}$ Department of thoracic and cardiovascular surgery - CHU Bordeaux- Pessac, France

${ }^{16}$ Detroit Medical Center, Department of

Cardiology, Detroit, MI, USA

${ }^{17}$ Department of Cardiology, Zucker School of Medicine at Hofstra/Northwell, NY, USA

${ }^{18}$ Division of Cardiothoracic Surgery

Department of Surgery Rutgers Robert Wood Johnson Medical School, New

Brunswick, NJ, USA

${ }^{19}$ Henry Ford Medical Center, Department of Interventional Cardiology and Structural

Heart, Detroit, MI, USA

*Author for correspondence: Email: tim.spelman@synergusrwe.com Received date: January 21, 2019 Accepted date: February 06, 2019 Published date: February 10, 2019 


\begin{tabular}{|c|c|c|c|}
\hline & Impella $2.5^{\circ}$ & Impella CP & Impella $5.0^{\circ}$ \\
\hline Flow & $<2.5 \mathrm{~L} / \mathrm{min}$ & $<4.0 \mathrm{~L} / \mathrm{min}$ & $<5 \mathrm{~L} / \mathrm{min}$ \\
\hline Catheter Size & $9 \mathrm{~F}$ & $9 \mathrm{~F}$ & $9 \mathrm{~F}$ \\
\hline Pump Insertion Size & $12 \mathrm{~F}$ & $14 \mathrm{~F}$ & $21 \mathrm{~F}$ \\
\hline Approved Duration & $\begin{array}{l}4 \text { days (US) } \\
5 \text { days (EU) }\end{array}$ & $\begin{array}{l}4 \text { days (US) } \\
5 \text { days (EU) }\end{array}$ & $\begin{array}{l}6 \text { days (US) } \\
10 \text { days (EU) }\end{array}$ \\
\hline FDA Approved Indications & $\begin{array}{l}\text { High Risk PCI } \\
\text { AMICS/PCCS }\end{array}$ & $\begin{array}{l}\text { High Risk PCI } \\
\text { AMICS/PCCS }\end{array}$ & AMICS/PCCS \\
\hline Insertion Sheath & $\begin{array}{l}13 \mathrm{~cm} \\
\text { Peel-Away } \\
\text { (femoral artery) }\end{array}$ & $\begin{array}{l}13 \mathrm{~cm} / 25 \mathrm{~cm} \\
\text { Peel-Away } \\
\text { (femoral artery) }\end{array}$ & $\begin{array}{l}6 \mathrm{~cm} \\
\text { Peel-Away } \\
\text { (axillary/femoral graft) }\end{array}$ \\
\hline Valve Interaction & Smooth Cannula & Smooth Cannula & Smooth Cannula \\
\hline
\end{tabular}

of Impella is currently available. The objective of this study was to present a pooled and up-to-date review of the survival and safety profile associated with the use of Impella devices in the cardiogenic shock (CS) and high-risk percutaneous coronary intervention (HRPCI) indications.

\section{Methods}

A systematic literature search was performed in Medline,
Medline In-Process, EMBASE and the CENTRAL bibliographic databases on the 30th April, 2017. Inclusion criteria are detailed in (Table 2). Only full-text peer-reviewed articles with 10 or more Impella patients supported for CS or HRPCI were included. The full search strategy is detailed in the Supplemental Material. Summary data for each included study is described in Supplemental Material. Benefit and safety outcomes analyzed and stratification groups used in the analysis are described in Table 3.

\section{Table 2: Inclusion criteria}

\begin{tabular}{|c|c|c|c|}
\hline \multicolumn{3}{|c|}{ Inclusion criteria } & \multirow[t]{2}{*}{ Exclusion criteria } \\
\hline Indication & Study type & Outcomes reportedc & \\
\hline $\begin{array}{l}\text { Cardiogenic shock } \\
\text { (CS) }\end{array}$ & $\begin{array}{l}\text { Multiple-patient observational and } \\
\text { experimental studies of Impella } \\
\text { device with } \geq 10 \text { Impella casesb } \\
\text { Patients implanted with Impella } \\
\text { devices in } 2004 \text { and later }\end{array}$ & & $\begin{array}{l}\text { Reviews } \\
\text { Conference abstracts } \\
\text { Device name was not reported in study } \\
\text { Study population of less than } 10 \\
\text { patients }\end{array}$ \\
\hline $\begin{array}{l}\text { Prophylactic use in } \\
\text { HRPCla }\end{array}$ & $\begin{array}{l}\text { Multiple-patient observational and } \\
\text { experimental studies of Impella } \\
\text { device with } \geq 10 \text { Impella casesb } \\
\text { Patients implanted with Impella } \\
\text { devices in } 2004 \text { and later }\end{array}$ & $\begin{array}{l}\text { Complications and safety } \\
\text { outcomes including stroke/ } \\
\text { TIA, MACE, bleeding, } \\
\text { hematoma, hemolysis, renal } \\
\text { dysfunction, limb ischemia, } \\
\text { device malfunction and } \\
\text { revascularization }\end{array}$ & $\begin{array}{l}\text { Studies of percutaneous ventricular } \\
\text { assist devices other than Impella } \\
\text { No clinical outcomes or no clinical } \\
\text { outcomes of interest reported } \\
\text { Mixed devices (results of Impella } \\
\text { reported combined with results of other } \\
\text { devices) } \\
\text { Mixed indications (results of patients } \\
\text { with CS or HRPCI reported combined } \\
\text { with results of patients treated with } \\
\text { other devices) } \\
\text { Other indication than cardiogenic shock } \\
\text { and HRPCI } \\
\text { Health economic studies } \\
\text { Prediatric population } \\
\text { Right ventricular support } \\
\text { Concomittant use of Impella and ECMO } \\
\text { Support during Balloon Aortic } \\
\text { Valvuloplasty (BAV) procedure } \\
\text { Support during Electrophysiology (EP) } \\
\text { procedure }\end{array}$ \\
\hline
\end{tabular}


Table 3: Stratification groups and study outcomes

\begin{tabular}{|c|c|}
\hline Stratification levels & Benefit \& safety events \\
\hline \multirow{2}{*}{$\begin{array}{l}\text { Indication } \\
\text { use of Impella as prophylactic circulatory support in patients } \\
\text { undergoing a non-emergent } \mathrm{HRPCl} \\
\text { emergent circulatory support in patient with cardiogenic shock } \\
\text { following an acute myocardial infarction (AMI), open heart } \\
\text { surgery (post-cardiotomy cardiogenic shock (PCCS)) or an acute } \\
\text { decompensated heart failure (ADHF) } \\
\text { Study type } \\
\text { randomized controlled trials (RCT) } \\
\text { non-randomized studies including prospective cohort studies, } \\
\text { retrospective cohorts, case series and chart reviews. }\end{array}$} & $\begin{array}{l}\text { Benefits } \\
\text { survival to next therapy } \\
\text { post-discharge survival (at 1,3,6 and } 12 \text { months where } \\
\text { available) }\end{array}$ \\
\hline & $\begin{array}{l}\text { Safety } 1 \\
\text { bleeding (including all forms of bleeding as reported, e.g. minor/ } \\
\text { major bleeding, bleeding required surgery or transfusion etc.) } \\
\text { hematoma (incliding all forms of hematoma) } \\
\text { hemolysis during hospitalization } \\
\text { leg/limb ischemia during hospitalization } \\
\text { stroke and/or TIA (during hospitalization, at } 1 \text { and } 3 \text { month) } \\
\text { MACE } \\
\text { device malfunction (where explicitly reported as either a "device } \\
\text { malfunction" or "device related technical failure"). }\end{array}$ \\
\hline \multicolumn{2}{|c|}{$\begin{array}{l}\text { AMI: Acute Myocardial Infraction; ADHF: Acute Decompensated Heart Failure; HRPCI: High Risk Percutaneous Coronary } \\
\text { Interventions; MACE: Major Adverse Cardiac Events; PCCS: Post-Cardiotomy Cardiogenic Shock; RCT: Randomized Controlled Trial; } \\
\text { TIA:Transient Ischemic Attack } \\
1 \quad \text { Other commonly-reported complications reported by the included studies that were assessed as not feasible for meta- } \\
\text { analysis (e.g. one specific type of outcome only reported in one study) are presented in Supplementary Material Sections 9-11. }\end{array}$} \\
\hline
\end{tabular}

\section{Statistical analyses}

Categorical variables were summarized using frequency and percentage. Continuous variables were summarized using mean and standard deviation (SD) or median and inter-quartile range (IQR) as appropriate. A random effects meta-analysis using DerSimonianLaird method was used to pool the various benefits and safety outcomes across included studies and expressed as proportions with $95 \%$ confidence intervals. Arcsine transformation of proportions was made for analysis of data from single-arm studies [8,9]. Inter-study heterogeneity was analyzed by Cochran's $Q$ and I2 statistics. A significant $\mathrm{p}$-vale of $\mathrm{Q}(\mathrm{p}<0.05)$ indicated that there might be significant heterogeneity between studies. Heterogeneity measured by I 2 was quantified as low, moderate, and high (low: 0-25\%; moderate 26-50\%; high 51-100\%) [9]. The primary results were limited to those outcomes associated with an I2 of less than $50 \%$. For all analyses, p-value $<0.05$ was considered significant. All analyses were conducted in R (R Foundation for Statistical Computing, Vienna, Austria) and validated in Stata version 15 (StataCorp, College Station, Texas) [10].

\section{Results}

\section{Patient characteristics}

A total of 33 publications [11-42] reported clinical outcomes for 2,827 patients with Impella support were included in the analysis (Tables 2 and 3). The mean (SD) age of patients in included studies was 64.9 (11.4) years. Males constituted $74.6 \%$ of patients. The median (IQR) number of patients treated with Impella devices in included studies was 36 (18-119). A total of $1,144(40.5 \%)$ patients were supported for CS, of which $890(78 \%)$ for AMICS (Acute Myocardial Infarction complicated by Cardiogenic Shock). A smaller group of $93(8 \%)$ patients had CS secondary to acute decompensated heart failure (ADHF) whilst 48 (4\%) patients had post-cardiotomy cardiogenic shock (PCCS). The median (IQR) duration of circulatory support was 43 hours (25-53 hours) for AMICS, 295 hours (231-358 days) for ADHF. The median (IQR) duration of support was 1.9 hours (1.5-2.1 hours) in the 1,715 patients supported prophylactically with Impella for HRPCI.

\section{Meta-analysis}

The pooled proportions of selected survival and complications (survival, stroke/TIA, MI, revascularization, MACE, bleeding, hemolysis, renal dysfunction, limb ischemia and device malfunction) across Impella device types within the cardiogenic shock indications (CS of any etiology and AMICS, ADHF-CS, PCCS) and HRPCI, are summarized in Tables 4, 5 and Supplemental Figures.

\section{Cardiogenic shock}

The pooled proportions of survival and complications across Impella device types for cardiogenic shock indications are summarized in Table 4.

\section{Survival}

In the two RCTs identified in the systematic search, survival at 30-days was reported to be $54 \%$ in both (29, 33). Additionally, in the IMPRESS trial $(\mathrm{n}=24)$ survival 


\begin{tabular}{|c|c|c|c|c|c|c|c|c|}
\hline Group & Outcome & $\begin{array}{l}\text { Patients } \\
\text { (N) }\end{array}$ & $\begin{array}{c}\text { Studies } \\
\text { pooled } \\
\text { (N) }\end{array}$ & $\begin{array}{c}\text { Pooled } \\
\text { proportion } \\
(95 \% \mathrm{Cl})\end{array}$ & 12 & $\begin{array}{c}\text { Degree } \\
\text { of } 12\end{array}$ & $\mathbf{Q}$ & $\begin{array}{l}\text { p-Value } \\
\text { for Q }\end{array}$ \\
\hline \multirow{10}{*}{ CS - prospective studies } & \multicolumn{8}{|l|}{ Survival } \\
\hline & Survival to next therapy & 26 & 2 & $0.887(0.597-1)$ & 0.74 & High & 3.79 & 0.052 \\
\hline & Survival at 30-days & 35 & 3 & $0.697(0.383-0.933)$ & 0.82 & High & 10.82 & 0.004 \\
\hline & Survival at 6 months & 25 & 2 & $0.658(0.334-0.916)$ & 0.77 & High & 4.38 & 0.036 \\
\hline & \multicolumn{8}{|l|}{ Complications } \\
\hline & Bleeding* & 15 & 3 & $0.247(0.042-0.547)$ & 0.82 & High & 9.89 & 0.007 \\
\hline & Hematoma** & 3 & 2 & $0.075(0.015-0.175)$ & 0 & Low & 0.06 & 0.803 \\
\hline & Device malfunction & 2 & 3 & $0.054(0.006-0.144)$ & 0.27 & Moderate & 2.68 & 0.261 \\
\hline & Hemolysis & 3 & 3 & $0.078(0.023-0.162)$ & 0 & Low & 0.66 & 0.72 \\
\hline & Limb ischemia & 1 & 2 & $0.059(0.005-0.167)$ & 0 & Low & 0.8 & 0.372 \\
\hline \multirow{14}{*}{$\begin{array}{l}\mathrm{CS} \text { - observational } \\
\text { retrospective studies }\end{array}$} & \multicolumn{8}{|l|}{ Survival } \\
\hline & Survival to next therapy & 178 & 8 & $0.717(0.565-0.847)$ & 0.83 & High & 39.16 & 0 \\
\hline & Survival to discharge & 352 & 10 & $0.63(0.539-0.716)$ & 0.75 & High & 37.27 & 0 \\
\hline & Survival at 30-days & 263 & 9 & $0.58(0.472-0.684)$ & 0.82 & High & 45.74 & 0 \\
\hline & Survival at 90-days & 77 & 4 & $0.626(0.539-0.709)$ & 0 & Low & 0.48 & 0.924 \\
\hline & Survival at 6 months & 28 & 3 & $0.583(0.442-0.718)$ & 0 & Low & 0.01 & 0.993 \\
\hline & Survival at 1 year & 109 & 5 & $0.463(0.321-0.609)$ & 0.8 & High & 22.06 & 0 \\
\hline & \multicolumn{8}{|l|}{ Complications } \\
\hline & Bleeding* & 106 & 10 & $0.157(0.089-0.239)$ & 0.8 & High & 38.48 & 0 \\
\hline & Hematoma** & 11 & 3 & $0.048(0.024-0.08)$ & 0 & Low & 0.72 & 0.699 \\
\hline & Device malfunction & 17 & 5 & $0.051(0.019-0.096)$ & 0.59 & High & 8.68 & 0.07 \\
\hline & Hemolysis & 60 & 7 & $0.143(0.042-0.291)$ & 0.93 & High & 58.45 & 0 \\
\hline & Limb ischemia & 11 & 6 & $0.042(0.023-0.067)$ & 0 & Low & 3.85 & 0.571 \\
\hline & Stroke/TIA in-hospital & 10 & 6 & $0.035(0.018-0.057)$ & 0 & Low & 2.97 & 0.705 \\
\hline \multirow{14}{*}{$\begin{array}{l}\text { AMICS - observational } \\
\text { retrospective studies }\end{array}$} & \multicolumn{8}{|l|}{ Survival } \\
\hline & Survival to next therapy & 97 & 3 & $0.704(0.532-0.851)$ & 0.64 & High & 5.87 & 0.053 \\
\hline & Survival to discharge & 278 & 6 & $0.563(0.464-0.659)$ & 0.71 & High & 16.4 & 0.006 \\
\hline & Survival at 30-days & 158 & 5 & $0.472(0.361-0.584)$ & 0.73 & High & 11.41 & 0.022 \\
\hline & Survival at 6 months & 20 & 2 & $0.588(0.421-0.746)$ & 0 & Low & 0 & 0.966 \\
\hline & Survival at 1 year & 71 & 3 & $0.372(0.247-0.506)$ & 0.69 & High & 5.84 & 0.054 \\
\hline & \multicolumn{8}{|l|}{ Complications } \\
\hline & Bleeding* & 88 & 5 & $0.214(0.159-0.276)$ & 0.42 & Moderate & 8.31 & 0.081 \\
\hline & Hematoma** & 10 & 2 & $0.049(0.023-0.083)$ & 0 & Low & 0.69 & 0.406 \\
\hline & Device malfunction & 8 & 3 & $0.025(0.011-0.045)$ & 0 & Low & 0.92 & 0.63 \\
\hline & Hemolysis & 30 & 3 & $0.081(0.056-0.111)$ & 0 & Low & 0.26 & 0.879 \\
\hline & Limb ischemia & 10 & 4 & $0.036(0.017-0.063)$ & 0 & Low & 3.2 & 0.362 \\
\hline & Renal Dysfunction & 98 & 3 & $0.459(0.147-0.79)$ & 0.97 & High & 15.95 & 0 \\
\hline & Stroke/TIA in-hospital & 9 & 4 & $0.037(0.018-0.062)$ & 0 & Low & 1.59 & 0.662 \\
\hline \multirow{6}{*}{$\begin{array}{l}\text { ADHF - observational } \\
\text { retrospective studies }\end{array}$} & \multicolumn{8}{|l|}{ Survival } \\
\hline & Survival to next therapy & 59 & 3 & $0.624(0.27-0.915)$ & 0.92 & High & 26.41 & 0 \\
\hline & Survival to discharge & 63 & 3 & $0.678(0.58-0.769)$ & 0 & Low & 0.59 & 0.743 \\
\hline & Survival at 30-days & 43 & 2 & $0.672(0.553-0.781)$ & 0 & Low & 0 & 0.945 \\
\hline & \multicolumn{8}{|l|}{ Complications } \\
\hline & Stroke/TIA in-hospital & 1 & 2 & $0.027(0.001-0.085)$ & 0.14 & Low & 1.16 & 0.281 \\
\hline * any ty & & & & & & & & \\
\hline
\end{tabular}




\begin{tabular}{|c|c|c|c|c|c|c|c|c|}
\hline Group & Outcome & $\begin{array}{l}\text { Patients } \\
\text { (N) }\end{array}$ & $\begin{array}{l}\text { Studies } \\
\text { pooled (N) }\end{array}$ & $\begin{array}{c}\text { Pooled } \\
\text { proportion } \\
(95 \% \mathrm{Cl})\end{array}$ & 12 & $\begin{array}{l}\text { Degree } \\
\text { of } 12\end{array}$ & $\mathbf{Q}$ & $\begin{array}{l}\text { p-Value } \\
\text { for } Q\end{array}$ \\
\hline \multirow{9}{*}{ HRPCI- Prospective studies } & \multicolumn{8}{|l|}{ Survival } \\
\hline & Survival at 30-days & 235 & 3 & $0.922(0.886-0.951)$ & 0 & Low & 0.2 & 0.906 \\
\hline & \multicolumn{8}{|l|}{ Complications } \\
\hline & Device malfunction & 0 & 2 & $0.004(0.002-0.029)$ & 0.15 & Low & 1.18 & 0.277 \\
\hline & Hemolysis & 2 & 2 & $0.09(0.017-0.212)$ & 0 & Low & 0.55 & 0.46 \\
\hline & MACE at 30-days & 39 & 3 & $0.153(0.112-0.2)$ & 0 & Low & 0.56 & 0.754 \\
\hline & Ml at 30-days & 33 & 2 & $0.135(0.095-0.18)$ & 0 & Low & 0.25 & 0.616 \\
\hline & $\begin{array}{l}\text { Revascularization } \\
\text { at } 30 \text {-days }\end{array}$ & 3 & 2 & $0.016(0.004-0.036)$ & 0 & Low & 0.07 & 0.792 \\
\hline & $\begin{array}{l}\text { Stroke/TIA at 30- } \\
\text { days }\end{array}$ & 0 & 2 & $0.003(0-0.014)$ & 0 & Low & 0.89 & 0.344 \\
\hline \multirow{17}{*}{$\begin{array}{l}\mathrm{HRPCI} \text { - observational } \\
\text { retrospective studies }\end{array}$} & \multicolumn{8}{|l|}{ Survival } \\
\hline & $\begin{array}{l}\text { Survival to next } \\
\text { therapy }\end{array}$ & 587 & 9 & $0.99(0.981-0.997)$ & 0 & Low & 2.75 & 0.949 \\
\hline & $\begin{array}{l}\text { Survival to } \\
\text { discharge }\end{array}$ & 938 & 6 & $0.979(0.964-0.99)$ & 0.24 & Low & 5.39 & 0.37 \\
\hline & Survival at 30-days & 398 & 6 & $0.961(0.94-0.977)$ & 0 & Low & 3 & 0.7 \\
\hline & Bleeding* & 35 & 7 & $0.074(0.035-0.126)$ & 0.72 & High & 18.93 & 0.004 \\
\hline & Hematoma** & 21 & 6 & $0.075(0.036-0.127)$ & 0.5 & High & 10.21 & 0.069 \\
\hline & Device malfunction & 1 & 5 & $0.007(0.001-0.017)$ & 0 & Low & 3.25 & 0.516 \\
\hline & Hemolysis & 12 & 7 & $0.014(0.008-0.021)$ & 0 & Low & 3.69 & 0.719 \\
\hline & Limb ischemia & 4 & 3 & $0.046(0.002-0.139)$ & 0.62 & High & 5.64 & 0.06 \\
\hline & MACE at 30-days & 17 & 3 & $0.051(0.03-0.077)$ & 0 & Low & 0.76 & 0.685 \\
\hline & Ml at 30-days & 1 & 4 & $0.008(0.001-0.02)$ & 0 & Low & 1.42 & 0.701 \\
\hline & Renal Dysfunction & 45 & 6 & $0.033(0.015-0.059)$ & 0.61 & High & 14.28 & 0.014 \\
\hline & $\begin{array}{l}\text { Revascularization } \\
\text { in-hospital }\end{array}$ & 5 & 3 & $0.009(0.003-0.017)$ & 0 & Low & 0.18 & 0.912 \\
\hline & $\begin{array}{l}\text { Revascularization } \\
\text { at 30-days }\end{array}$ & 3 & 4 & $0.019(0.004-0.044)$ & 0.15 & Low & 3.54 & 0.316 \\
\hline & $\begin{array}{l}\text { Stroke/TIA peri- } \\
\text { procedural }\end{array}$ & 0 & 2 & $0.006(0-0.022)$ & 0 & Low & 0.31 & 0.578 \\
\hline & $\begin{array}{l}\text { Stroke/TIA in- } \\
\text { hospital }\end{array}$ & 0 & 5 & $0.002(0-0.008)$ & 0.1 & Low & 3.42 & 0.49 \\
\hline & $\begin{array}{l}\text { Stroke/TIA at 30- } \\
\text { days }\end{array}$ & 1 & 4 & $0.008(0.001-0.02)$ & 0 & Low & 1.15 & 0.764 \\
\hline * any type of bleeding & & & & & & & & \\
\hline
\end{tabular}

at 6-months was $50 \%$ (29). Survival at 90-days in the CS of any etiology in retrospective cohort was $62.6 \%$ (95\%CI: $53.9 \%-70.9 \%)$ and survival at 6 months was $58.3 \%(95 \% \mathrm{CI}: 44.2-71.8 \%)$. Other survival outcomes including survival to next therapy and survival to discharge were associated with unacceptably high heterogeneity and were thus considered unreliable.
Similarly, in prospective studies of CS of any etiology, the outcomes on survival were similarly limited by excessive heterogeneity. Survival at 6 months in the AMICS subgroup was $58.8 \% \quad(95 \% \mathrm{CI}: \quad 42.1 \%$ $74.6 \%$ ). In the subgroup of ADHF patient's survival to discharge was $67.8 \%$ (95\%CI: 58\%-76.9\%), whilst 30-day survival was $67.2 \%$ (95\%CI: $55.3 \%-78.1 \%$ ). 


\section{Complications}

In the IMPRESS trial, bleeding incidence among Impella patients was $33.3 \%$ and hemolysis $8.3 \%$ (29), while in the ISAR-SHOCK trial $(n=26)$ no bleeding was observed (33). Across prospective CS studies, the pooled rates of hemolysis (7.8\%; 95\%CI: 2/3\%-16.2\%) and limb ischemia (5.9\%; 95\%CI: 0.5\%-16.7\%) were low. Similarly, in the retrospective CS studies the low rates of in-hospital stroke (3.5\%; 95\%CI: 1.8\%-5.7\%) and limb ischemia (4.2\%; 95\%CI: $2.3 \%-6.7 \%)$ were observed. When retrospective studies were pooled for the subgroup of AMICS patients, event rates within the observational retrospective studies were generally low (device malfunction $2.5 \%(1.1 \%-4.5 \%)$; in-hospital stroke 3.7\% (95\%CI: 1.8\%-6.2\%); limb ischemia 3.6\% (95\%CI:1.7\%-6.3\%), hematoma 4.9\% (95\% CI:2.3\%8.3\%), hemolysis $8.1 \%$ (95\%CI: $5.6 \%-11.1 \%$ ). The exception was bleeding, observed in $21.4 \%$ of patients (95\%CI: $15.9 \%-27.6 \%)$. In the ADHF group inhospital stroke rate was $2.7 \%$ (95\%CI: $0.01 \%-8.5 \%$ ).

\section{High-risk percutaneous coronary intervention}

The pooled proportions of survival and complications across Impella device types for high risk PCI are summarized in Table 5.

\section{Survival}

A single RCT (PROTECT II) comparing HRPCI patients on Impella $2.5(\mathrm{n}=225)$ to patient on intraaortic balloon pump $(n=223)$ reported $92.4 \%$ of patients randomized to Impella 2.5 had survived to 30 -days post insertion, decreasing marginally to $87.9 \%$ at 90-days (28). For the HRPCI prospective group, 30-day survival was 92.2\% (95\%CI: 88.6\%-95.1\%). Survival was very high within retrospective studies of patients supported prophylactically with Impella 2.5 for HRPCI. Survival to next therapy was $99 \%$ (95\%CI: 98.1\%-99.7\%), $97.9 \%$ at discharge was (95\%CI: $96.4 \%-99 \%$ ) and $96.1 \%$ at 30 -days (95\%CI: $94 \%-$ $97.7 \%)$.

\section{Complications}

The incidence of stroke/TIA in the PROTECT II intention-to-treat (ITT) Impella arm was low - from $0.0 \%$ at 30 -days to $0.9 \%$ at 90 -days. Acute renal dysfunction was associated with $4.0 \%$ of insertions at both 30 and 90-days (28). The use of Impella 2.5 in HRPCI patients (prospective study cohort) was associated with low rates of strokes/TIA at 30-days (0.3\%; 95\%CI: 0\%-1.4\%), device malfunction (0.4\%; 95\% CI: $0.02 \%-2.9 \%)$, revascularization at 30 -days (1.6\%; 95\%CI: $0.4 \%-3.6 \%$ ) and hemolysis (9\%;
95\%CI: $1.7 \%-21.2 \%$ ). The rate of MACE (Major Adverse Cardiac Events) at 30-days was 15.3\% (95\%CI: $11.2 \%-20 \%$ ) and MI (myocardial infarction) at 30-days was $13.5 \%$ (95\%CI: $9.5 \%-18 \%)$. In the retrospective studies cohort, the rate of strokes/TIA at 30-days was $0.8 \%$ (95\%CI: $0.1 \%-2 \%)$ device malfunction $(0.7 \%$; $95 \%$ CI $0.01 \%-1.7 \%)$, revascularization at 30 -days (1.9\%; 95\%CI $0.4 \%-4.4 \%)$ and hemolysis (1.4\%; 95\%CI $0.8 \%-2.1 \%)$. The rate of MACE at 30-days was $5.1 \%$ (95\% CI: 3\%-7.7\%) and MI at 30-days was $0.8 \%$ (95\%CI: $0.1 \%-2 \%)$.

\section{Device type}

The pooled proportions of survival and complications disaggregated by Impella device types within the cardiogenic shock indication are summarized in Supplemental Material.

\section{Survival}

Across all indications, 67.8\% (95\%CI: 58\%-76.9\%) of patients supported with Impella 5.0 survived to discharge. This fell marginally to $67.2 \%$ survival at 30 days (95\%CI: 55.3\%-78.1\%). All results of survival outcomes from the Impella 2.5 group had unacceptably high heterogeneity and were thus considered unreliable.

\section{Complications}

In-hospital stroke/TIA was again low, associated with only $2.9 \%$ (95\%CI: $1.1 \%-5.7 \%)$ of Impella 2.5/CP insertions and 2.7\% (95\%CI: $0.1 \%-8.5 \%)$ of Impella 5.0 supports. Consistent with the other indications and study types analyzed, in-hospital bleeding was associated with $23.1 \%$ (95\%CI: $16.7 \%$ $30.3 \%$ ) of Impella $2.5 / \mathrm{CP}$ insertions. Similarly, device malfunction was again low associated with just $2.3 \%$ of Impella $2.5 / \mathrm{CP}$ insertions (95\%CI: $0.9 \%-4.3 \%$ ). For Impella $2.5 / \mathrm{CP}$, hemolysis was reported in $8.6 \%$ (95\%CI: $5.7 \%-12 \%$ ) of insertions while for Impella 5.0 it was $6.9 \%$ (95\%CI: $1.8 \%-15 \%)$. The rates of limb ischemia in Impella $2.5 / \mathrm{CP}$ was $4.7 \%$ (95\% CI: $2.1 \%$ $8.2 \%)$ and $3.6 \%$ (95\%CI: $0.3 \%-10 \%$ ) in Impella 5.0 .

\section{Discussion}

Impella devices were associated with good survival and generally low rates of complications and safety outcomes across all combinations of indication and study types analyzed. In the absence of sufficiently powered randomized clinical trials covering relevant indications and patient cohorts, the presented metaanalysis provides the best evidence to date and confirms observations from individual studies that the use of Impella in CS is likely to be safe and effective. It further 
extends the existing evidence base by demonstrating that these low event rates and favorable survival outcomes are generally consistent across both the indication and the study design used to study Impella outcome data.

Survival in CS secondary to either ADHF or AMI supported with Impella was particularly encouraging, with pooled 90-day survival across both indications at $62.6 \%$. When the analysis was limited to the ADHF cohort, an indication characterized by the use of the more powerful Impella 5.0 device, survival to discharge was $67.8 \%$ (with an upper limit high of $83.0 \%$ ) whilst survival at 30-days was $67.2 \%$. In the context of ADHF, the 5.0 device is employed to reverse tissue hypoxemia, end organ dysfunction, and cardiorenal syndrome facilitating bridge to recovery, durable LVAD insertion of heart transplantation [25].

The relatively high rates of survival consistently observed across these often severely decompensated patients supports the effectiveness of the Impella 5.0 as a "bridge to decision" in ADHF [25]. Survival in the AMICS patients at 6 months was $58.8 \%$ (when the meta-analysis was limited to case series). Elsewhere, prophylactic Impella support for patients undergoing HRPCI was associated consistently high survival rates at 30 -days (92.2\% in prospective studies and $96.1 \%$ in retrospective studies), in line with expectations.

Notably, the rate of stroke/TIA was particularly low - regardless of indication, device type or study design. The maximum inpatient stroke rate observed amongst those pooled analyses associated with acceptable heterogeneity was $2.7 \%$ in both the ADHF case series and in the pooled CS retrospective observational studies it was 3.5\%. In-hospital stroke rate was 3.7\% in the AMICS and just $0.02 \%$ of the HRPCI retrospective studies group. This is broadly consistent with the low rates of stroke/TIA reported in the Impella arm of the pivotal PROTOCOL II study; which observed $0.0 \%$ and $0.9 \%$ stroke or TIA rates at 30 and 90 -days respectively.

Limb ischemia is a significant risk for CS patients managed with a combination of mechanical support and catecholamine therapy. However, our meta-analysis suggests that limb ischemia is a relatively infrequent event at $5.9 \%$ of patients in the pooled CS prospective studies group (upper limit 16.7\%) and $4.2 \%$ in CS retrospective group (upper limit 6.7\%). In the AMICS subgroup limb ischemia rate was $4.4 \%$. Bleeding events were reported in $23.5 \%$ of the AMICS subgroup,
Hemolysis rates were consistently low across indication/ study type groups, ranging from a high of $8.8 \%$ in the AMICS PCI case series cohort to just $1.4 \%$ of the HRPCI retrospective subgroup. In the retrospective studies device malfunction was low in both the AMICS PCI $s$ (2.5\%) and the HRPCI subgroups (0.7\%).

Whilst this meta-analysis provides the largest pooling of survival and complications to date in CS and HRPCI patients on Impella support, it does have a number of limitations. Firstly, it is not a comparative analysis and thus should not be used to make inferences around the exact benefit attributable to Impella relative to any other left ventricular support device in these specific clinical scenarios, with regards to either efficacy or in terms of harm avoided. Secondly, a large proportion of eligible studies included in the meta-analyses were lowquality case series. This led, in part, to the unacceptably high levels of heterogeneity for several key outcomes. However, by stratifying the meta-analysis by the level of evidence (i.e. study type) we were able to statistically demonstrate for the first time that those favorable survival and low incidence of adverse event signals previously only observed in individual studies were broadly consistent across study types (randomized trial, prospective cohort, retrospective, case series) suggesting these signals are genuine. An appropriately powered clinical trial and/or larger prospective cohort study, preferably of longer follow-up duration than the studies included here, would be required to better characterize the benefit of Impella in these patient cohort, particularly in relation to competitor support devices.

\section{Funding}

This study was supported by Abiomed Inc. The sponsor had no influence or editorial control over the content of the study.

\section{Conflicting Interests}

Natalia M Stelmaszuk-Zadykowicz, Sun Sun and Tim Spelman are employees of Synergus AB - MedTech consulting company and received consulting fees from Abiomed Inc. Jonathan Hill, Bernhard Schieffer, Andreas Schäfer have received honoraria for speaking and chairing at symposia. The other authors report no conflicts.

\section{Acknowledgements}

We would like to thank Vladica Veličković for his contribution to this project. 


\section{References}

1. Khalid L, Dhakam SH. A review of cardiogenic shock in acute myocardial infarction. Curr Cardiol Rev. 4(1): 34-40 (2008).

2. Levine GN, Bates ER, Blankenship JC, et al. 2011 ACCF/ AHA/SCAI Guideline for Percutaneous Coronary Intervention. A report of the American College of Cardiology Foundation/ American Heart Association Task Force on Practice Guidelines and the Society for Cardiovascular Angiography and Interventions. J Am Coll Cardiol. 58(24): e44-122 (2011).

3. Reynolds HR, Hochman JS. Cardiogenic shock: current concepts and improving outcomes. Circulation. 117(5): 686-697 (2008).

4. Stretch R, Sauer CM, Yuh DD, et al. National trends in the utilization of short-term mechanical circulatory support: incidence, outcomes, and cost analysis. J Am Coll Cardiol. 64(14): 1407-1415 (2014).

5. http: //www.abiomed.com/.

6. Cheng JM, den Uil CA, Hoeks SE, et al. Percutaneous left ventricular assist devices vs. intra-aortic balloon pump counterpulsation for treatment of cardiogenic shock: a metaanalysis of controlled trials. Eur Heart J. 30(17): 2102-2108 (2009).

7. Maini B, Scotti DJ, Gregory D. Health economics of percutaneous hemodynamic support in the treatment of highrisk cardiac patients: a systematic appraisal of the literature. Expert Rev Pharmacoecon Outcomes Res. 14(3): 403-416 (2014).

8. McDonald JH. Handbook of biological statistics. Baltimore, Sparky House Publishing Baltimore, Maryland, USA (2009).

9. Schwarzer G, Carpenter JR, Rucker G. Meta-Analysis with R. Cham: Springer International Publishing (2015).

10. StataCorp. Stata Statistical Software: Release 14. College Station, TX: StataCorp LP (2015).

11. Badiye AP, Hernandez GA, Novoa I, et al. Incidence of Hemolysis in Patients with Cardiogenic Shock Treated with Impella Percutaneous Left Ventricular Assist Device. ASAIO J. 62(1): 11-14 (2016).

12. Bansal A, Bhama JK, Patel R, et al. Using the minimally invasive impella 5.0 via the right subclavian artery cutdown for acute on chronic decompensated heart failure as a bridge to decision. Ochsner J. 16(3): 210-216 (2016).

13. Basir MB, Schreiber TL, Grines CL, et al. Effect of early initiation of mechanical circulatory support on survival in cardiogenic shock. Am J Cardiol. 119(6): 845-851 (2017).

14. Burzotta F, Paloscia L, Trani C, et al. Feasibility and longterm safety of elective Impella-assisted high-risk percutaneous coronary intervention: a pilot two-centre study. J Cardiovasc Med (Hagerstown). 9(10): 1004-1010 (2008).

15. Casassus F, Corre J, Leroux L, et al. The use of Impella 2.5 in severe refractory cardiogenic shock complicating an acute myocardial infarction. J Interv Cardiol. 28(1): 41-50 (2015).

16. Dixon SR, Henriques JP, Mauri L, et al. A prospective feasibility trial investigating the use of the Impella 2.5 system in patients undergoing high-risk percutaneous coronary intervention (The PROTECT I Trial): initial U.S. experience. JACC Cardiovasc Interv. 2(2): 91-96 (2009).

17. Ferreiro JL, Gomez-Hospital JA, Cequier AR, et al. Use of Impella Recover LP 2.5 in elective high risk percutaneous coronary intervention. Int J Cardiol. 145(2): 235-237 (2010).

18. Flaherty MP, Pant S, Patel SV, et al. Hemodynamic support with a microaxial percutaneous left ventricular assist device (impella) protects against acute kidney injury in patients undergoing highrisk percutaneous coronary intervention. Circ Res. 120(4): 692700 (2017)

19. Griffith BP, Anderson MB, Samuels LE, et al. The RECOVER I: a multicenter prospective study of Impella 5.0/LD for postcardiotomy circulatory support. $J$ Thorac Cardiovasc Surg. 145(2): 548-554 (2013).

20. Henriques JP, Remmelink M, Baan J, et al. Safety and feasibility of elective high-risk percutaneous coronary intervention procedures with left ventricular support of the Impella Recover LP 2.5. Am J Cardiol. 97(7): 990-992 (2006).

21. Joseph SM, Brisco MA, Colvin M, et al. Women with cardiogenic shock derive greater benefit from early mechanical circulatory support: an update from the cVAD Registry. J Interv Cardiol. 29(3): 248-256 (2016).

22. Kovacic JC, Nguyen HT, Karajgikar R, et al. The Impella Recover 2.5 and TandemHeart ventricular assist devices are safe and associated with equivalent clinical outcomes in patients undergoing high-risk percutaneous coronary intervention. Catheter Cardiovasc Interv. 82(1): E28-37 (2013).

23. Lauten A, Engstrom AE, Jung C, et al. Percutaneous leftventricular support with the Impella-2.5-assist device in acute cardiogenic shock: results of the Impella-EUROSHOCKregistry. Circ Heart Fail. 6(1): 23-30 (2013).

24. Lemaire A, Anderson MB, Lee LY, et al. The Impella device for acute mechanical circulatory support in patients in cardiogenic shock. Ann Thorac Surg. 97(1): 133-138 (2014).

25. Lima B, Kale P, Gonzalez-Stawinski GV, et al. Effectiveness and Safety of the Impella 5.0 as a Bridge to Cardiac Transplantation or Durable Left Ventricular Assist Device. Am J Cardiol. 117(10): 1622-1628 (2016).

26. Mastroianni C, Bouabdallaoui N, Leprince P, et al. Short-term mechanical circulatory support with the Impella 5.0 device for cardiogenic shock at La Pitie-Salpetriere. Eur Heart J Acute Cardiovasc Care. 6(1): 87-92 (2017).

27. O'Neill WW, Dixon S, Massaro J, et al. The current use of impella 2.5 in acute myocardial infarction complicated by cardiogenic shock: Results from the uspella registry. J Interv Cardiol.. 62(18): B137 (2013)

28. O’Neill WW, Kleiman NS, Moses J, et al. A prospective, randomized clinical trial of hemodynamic support with Impella 2.5 versus intra-aortic balloon pump in patients undergoing high-risk percutaneous coronary intervention: the PROTECT II study. Circulation. 126(14): 1717-1727 (2012).

29. Ouweneel DM, Eriksen E, Sjauw KD, et al. Percutaneous Mechanical Circulatory Support Versus Intra-Aortic Balloon Pump in Cardiogenic Shock After Acute Myocardial Infarction. J Am Coll Cardiol. 69(3): 278-287 (2017).

30. Schreiber T, Wah Htun W, Blank N, et al. Real-world supported unprotected left main percutaneous coronary intervention with impella device; data from the USpella registry. Catheter Cardiovasc Interv. 1;90(4): 576-581 (2017).

31. Schroeter MR, Kohler H, Wachter A, et al. Use of the Impella Device for Acute Coronary Syndrome Complicated by Cardiogenic Shock - Experience From a Single Heart Center 
With Analysis of Long-term Mortality. J Invasive Cardiol. 28(12): 467-472 (2016).

32. Schwartz BG, Ludeman DJ, Mayeda GS, et al. High-risk percutaneous coronary intervention with the TandemHeart and Impella devices: a single-center experience. J Invasive Cardiol. 23(10): 417-424 (2011).

33. Seyfarth M, Sibbing D, Bauer I, et al. A randomized clinical trial to evaluate the safety and efficacy of a percutaneous left ventricular assist device versus intra-aortic balloon pumping for treatment of cardiogenic shock caused by myocardial infarction. J Am Coll Cardiol. 52(19): 1584-1588 (2008).

34. Sjauw KD, Konorza T, Erbel R, et al. Supported high-risk percutaneous coronary intervention with the Impella 2.5 device the Europella registry. J Am Coll Cardiol. 54(25): 2430-2434 (2009).

35. Vase H, Christensen S, Christiansen A, et al. The Impella CP device for acute mechanical circulatory support in refractory cardiac arrest. Resuscitation. 112: 70-74 (2017).

36. Alasnag MA, Gardi DO, Elder M, et al. Use of the Impella 2.5 for prophylactic circulatory support during elective high-risk percutaneous coronary intervention. Cardiovasc Revasc Med. 12(5): 299-303 (2011).

37. Cohen MG, Matthews R, Maini B, et al. Percutaneous left ventricular assist device for high-risk percutaneous coronary interventions: Real-world versus clinical trial experience. $\mathrm{Am}$ Heart J. 170(5): 872-879 (2015).

38. Dangas GD, Kini AS, Sharma SK, et al. Impact of hemodynamic support with Impella 2.5 versus intra-aortic balloon pump on prognostically important clinical outcomes in patients undergoing high-risk percutaneous coronary intervention (from the PROTECT II randomized trial). Am J Cardiol. 113(2): 222228 (2014).

39. Higgins J, Lamarche Y, Kaan A, et al. Microaxial devices for ventricular failure: a multicentre, population-based experience. Can J Cardiol. 27(6): 725-730 (2011).

40. Liu W, Mukku VK, Gilani S, et al. Percutaneous Hemodynamic Support (Impella) in Patients with Advanced Heart Failure and/ or Cardiogenic Shock Not Eligible to PROTECT II Trial. Int J Angiol. 22(4): 207-212 (2013).

41. Pieri M, Contri R, Winterton D, et al. The contemporary role of Impella in a comprehensive mechanical circulatory support program: a single institutional experience. BMC Cardiovasc Disord. 15: 126 (2015).

42. Iliodromitis KE, Kahlert P, Plicht B, et al. High-risk PCI in acute coronary syndromes with Impella LP 2.5 device support. Int $J$ Cardiol. 153(1): 59-63 (2011). 